mother and baby discharged home. At five months breast feeding was discontinued. The mother remained well and the baby had achieved all her expected developmental milestones at six months and one year. At no time did we observe any behavioural or motor abnormalities.

\section{Discussion}

The secretion of haloperidol in breast milk has been reported ${ }^{1}$ but the amount of drug ingested by the breast-fed infant has not been measured. Our results confirm that appreciable amounts of haloperidol may be secreted in breast milk and thus ingested by the infant.

Adverse behavioural effects may occur in the young of nursing animals given haloperidol. ${ }^{2}$ There have been no reports of adverse effects in infants breast fed by mothers taking haloperidol, though such infants apparently receive a substantial amount of the drug. In our case the baby's development was closely monitored and no behavioural abnormalities were noted. Normal developmental milestones were reached by the age of one year.

Our results suggest that, though haloperidol when administered in therapeutic doses is secreted in breast milk, ingestion for less than three weeks does not have a deleterious effect on the infant's development.

We thank Dr A I M Glen and Dr H H Gebbie for permission to study a patient under their care.

\section{References}

1 Stewart RB, Karas B, Springer PK. Haloperidol excretion in human milk. Am f Psychiatry 1980;137:849-50.

${ }^{2}$ Lundborg P. Abnormal ontogeny in young rabbits after chronic administration of haloperidol to the nursing mothers. Brain Res 1972 $44: 684-7$.

\title{
Malaria diagnosis by enzyme-linked immunosorbent assays
}

\author{
DENNIS E BIDWELL, ALISTER VOLLER
}

\begin{abstract}
Enzyme-linked immunosorbent assays (ELISA) for detecting malarial parasites in blood were tested in uninfected monkeys and in monkeys infected with Plasmodium falciparum. A double antibody sandwich ELISA detected one malarial cell per $10^{3}$ uninfected cells, and an inhibition ELISA detected one infected cell per $10^{4}$ uninfected erythrocytes.

These methods are not yet as sensitive as conventional blood-film examinations, in which a well-trained microscopist might be expected to detect one malarial cell per $10^{6}$ erythrocytes. Nevertheless, ELISA offers an objective means of detecting malaria and is particularly advantageous since up to 100 samples may be processed simultaneously.
\end{abstract}

\section{Introduction}

The conventional way of diagnosing malaria is by visual microscopical detection of malaria parasites in stained blood films. This is an efficient procedure if well-trained staff are available, when very low parasitaemias may be detected. Malaria is only rarely encountered in most pathological laboratories, however, and parasites are often overlooked. Even in areas where malaria is endemic blood-smear examination may be unreliable unless a system of random checking is implemented.

Immunoassay is an attractive and effective way of measuring antigens and antibodies. The methods are specific and sensitive, and often the same method may be used for a wide variety of applications. Routine screening of blood for hepatitis B surface

\footnotetext{
Nuffield Laboratories of Comparative Medicine, Institute of Zoology, Zoological Society of London, London NW1 4RY

DENNIS E BIDWELL, PHD, research assistant

Department of Clinical Tropical Medicine, London School of Hygiene and Tropical Medicine, London WC1 7HT

ALISTER VOLLER, DSC, MRCPATH, reader in immunology of parasitic diseases
}

antigen shows that immunoassays may be done efficiently on a large scale. For malaria, most immunoassays have been set up for the measurement of malarial antibody values, ${ }^{1}$ which may yield valuable epidemiological data on malaria transmission. Several years ago extensive studies were carried out on the type and prevalence of Plasmodium falciparum antigens in West Africa, ${ }^{2}$ but the purpose of the studies was analytical and the methods were not designed to detect slight parasitaemia. More recently isotopic methods have been used successfully to assay malarial antigens in the blood of experimentally infected animals ${ }^{3}$ and of naturally infected people. ${ }^{4}$ Radioimmunoassay techniques are not, however, suitable for use in most parasitological laboratories. This paper considers the use of enzyme-linked immunosorbent assays to detect $P$ falciparum parasites in blood.

\section{Materials and methods}

Antiserum -A high-titre antiserum to $P$ falciparum was obtained from an aotus monkey that had been infected and repeatedly challenged with $P$ falciparum (Palo Alto). The immunoglobulin fraction of the serum was prepared for coating microplates and part of it labelled with horse-radish peroxidase as described previously. ${ }^{5}$

Antigen-Aotus monkeys were infected with $P$ falciparum, and when parasitaemias were $20 \%$ or above blood was taken into heparin. The erythrocytes were separated by centrifugation and washed free of plasma. Soluble malarial antigen was obtained by sonic disruption of the infected erythrocytes. ${ }^{6}$

Test samples-Peripheral blood samples were collected into heparinised capillary tubes from uninfected saimiri monkeys and saimiri monkeys infected with $P$ falciparum. Blood films were made at the same time and stained with Giemsa.

ELISA

Two versions of microplate ELISA were used-namely, the double antibody sandwich and the inhibition methods. Full technical details of these have been reported. ${ }^{5}$

Double antibody sandwich ELISA-Polyvinyl microplates were coated with immunoglobulin $(10 \mu \mathrm{g} / \mathrm{ml})$ from the antimalarial serum. The plates were then coated with $5 \%$ bovine serum albumin. After washing the plates were dried and then sealed in aluminium foil pouches in which they were stored at $4^{\circ} \mathrm{C}$. 
The test was carried out as follows. (1) Phosphate-buffered saline Tween 20 fetal bovine serum $(100 \mu \mathrm{l})$ was added to each well of a microplate (phosphate-buffered saline $0.15 \mathrm{~mol} / 1(\mathrm{pH} 7 \cdot 2), 0.05 \%$ Tween $20,10 \%$ fetal bovine serum). Each test blood sample $(20 \mu \mathrm{l})$ was added to the diluent in individual wells and incubated for two hours at $37^{\circ} \mathrm{C}$, after which the plates were washed. (2) Diluted conjugate (peroxidaselabelled antimalarial serum) $(100 \mu \mathrm{l})$ was added to each well and incubated for two hours at $37^{\circ} \mathrm{C}$. The plates were then washed. (3) Enzyme substrate solution (orthophenylenediamine) $(200 \mu \mathrm{l})$ was added to each well and incubated for 20 minutes at room temperature, after which $50 \mu \mathrm{l}$ sulphuric acid $2.5 \mathrm{~mol} / \mathrm{l}$ was added to each well to stop the reaction. The absorbance of the contents of each well was read at $492 \mathrm{~nm}$ and results expressed as absorbance units.

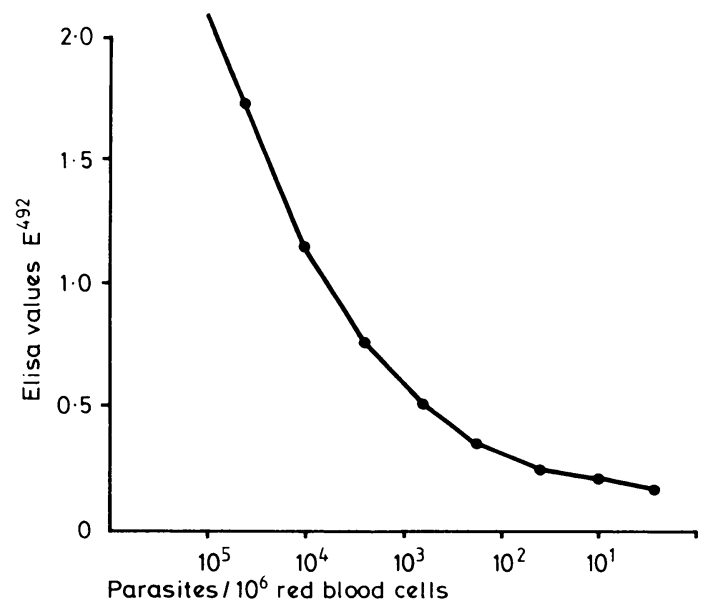

FIG 1-Relation of malaria parasitaemia and ELISA values obtained by double antibody sandwich method.

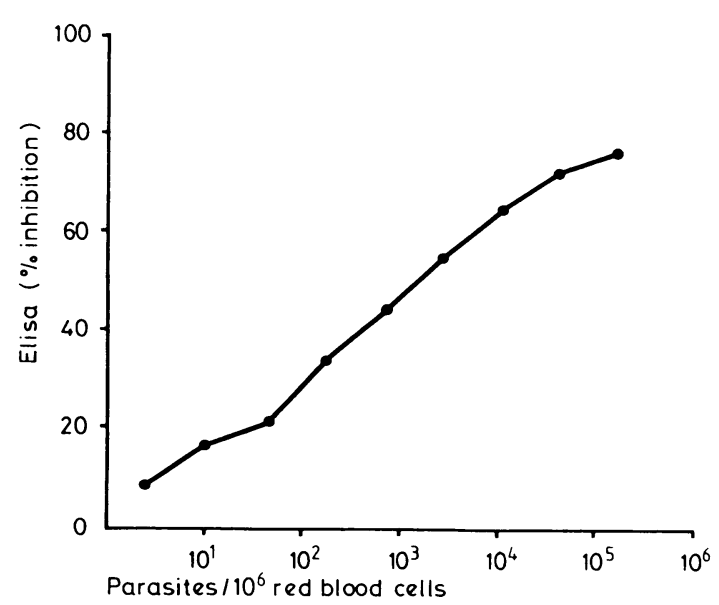

FIG 2-Relation of malaria parasitaemia and ELISA values obtained by inhibition method.

Inhibition ELISA-Polystyrene microplates were coated with $P$ falciparum antigen and the coated plates washed, dried and stored at $4^{\circ} \mathrm{C}$ in aluminium foil bags. The test was carried out as follows. (1) The test blood sample $(20 \mu \mathrm{l})$ was mixed with $400 \mu \mathrm{l}$ of the optimally diluted peroxidase-labelled antimalarial conjugate and incubated in a tube for at least two hours at room temperature. (2) Samples $(200 \mu \mathrm{l})$ from the tubes were added to wells in the malarialantigen-coated microplates and incubated for three hours at room temperature. The plates were then washed. (3) Enzyme substrate solution $(200 \mu \mathrm{l})$ was added to each well and incubated for 30 minutes at room temperature, after which the reaction was stopped by adding $50 \mu \mathrm{l}$ sulphuric acid to each well. The absorbance of the contents of each well was read at $492 \mathrm{~nm}$. Results are expressed as the percentage inhibition of the reaction product generated by tubes containing only the enzyme-labelled antimalarial conjugate (in the absence of a test sample).

\section{Results}

The dose response curves of the double antibody sandwich ELISA and the inhibition ELISA (figs 1 and 2) were established by carrying $\mathbb{Q}$ out tests on a blood sample positive for $P$ falciparum that was serially $\underset{c}{c}$ diluted in uninfected blood. The double antibody sandwich assay yielded positive results when there was one malarial cell $/ 10^{3}$ uninfected erythrocytes, and the inhibition assay detected levels above one infected cell $/ 10^{4}$ uninfected erythrocytes.

The table shows the results of inhibition ELISA tests on a panel of blood samples collected from uninfected saimiri monkeys and from monkeys infected with $P$ falciparum.

Results of ELISA inhibition tests for malarial antigen in blood of monkeys infected with $P$ falciparum and control monkeys

\begin{tabular}{|c|c|c|c|c|c|c|}
\hline \multicolumn{5}{|c|}{ Source of blood sample } & $\begin{array}{l}\text { Parasites } / 10^{4} \text { red } \\
\text { blood cells }\end{array}$ & $\begin{array}{l}\% \text { ELISA } \\
\text { inhibition }\end{array}$ \\
\hline \multicolumn{6}{|c|}{10 uninfected saimiri monkeys } & $1 \cdot 2^{*}$ \\
\hline \multicolumn{5}{|c|}{ Saimiri monkey infected with $P$ falciparum } & 1 & 35 \\
\hline ", & ," & ", & " & , & 17 & 48 \\
\hline ", & ", & ", & ", & " & 17 & 53 \\
\hline ", & ", & ", & ", & ", & 76 & 49 \\
\hline ", & ", & " & " & $"$ & 200 & 72 \\
\hline ", & ", & ", & ” & " & 750 & 68 \\
\hline „, & ", & " & ", & ", & 756 & 74 \\
\hline
\end{tabular}

*Blood from eight uninfected monkeys yielded no inhibition, blood from one yielded $0.5 \%$, and blood from one other yielded $10 \%$

\section{Discussion}

Our studies show that ELISA may be used to detect malarial 윽 parasites in infected blood. At present the level of detectability $\omega_{0}$ is not nearly as good as that that may be expected from a well- 3 trained microscopist, who might be expected to detect one malarial cell per $10^{6}$ erythrocytes. This, however, is much higher than the level of detection that might be achieved in the average $\infty$ pathological laboratory. The immunoassay method of course requires special skills, but these are no different from those needed in many other immunoassays.

The inhibition ELISA was the better of the two methods investigated in this study, and it could clearly be made even more sensitive if monoclonal antibody to malarial parasites was used in the conjugate. This would also permit well-defined specificity.

If the immunoassay methods could be improved to achieve the same level of sensitivity as blood-smear screening then they would be particularly advantageous since multiple samples (up to 100) might be processed simultaneously. This would lead to a dramatic reduction in the effort needed for large malaria surveys in the field.

This investigation received financial support from the UNDP/ World Bank/WHO Special Programme for Research and Training in Tropical Diseases. We are most grateful for the technical help of Daphne Green.

\section{References}

1 Voller A, Meuwissen JHET, Verhave JP. Methods for measuring the immunological response to plasmodia. In: Kreier JP, ed. Malaria. New York: Academic Press, 1980:67-110.

2 Wilson RJM. Antigens and antibodies associated with $\mathbf{P}$ falciparum infections in West Africa. Trans $R$ Soc Trop Med Hyg 1970;64:547-54.

3 Mackey L, Perrin L, Leemans E, Lambert PH. The diagnosis of malaria infections using a solid phase radioimmunoassay for the detection of $\square$ malaria antigens. Parasitology 1980;80:171-82.

4 Mackey L, McGregor IA, Lambert PH. Diagnosis of Plasmodium falciparum infection using a solid phase radioimmunoassay for the detection of malaria antigen. Bull WHO 1980;58:439-44.

5 Voller A, Bidwell DE, Bartlett A. Enzyme linked immunosorbent assays. In: Rose RN, Friedman H, eds. Manual of clinical immunology. Washington, DC: American Society for Microbiology, 1980:359-71

6 Voller A, Bartlett A, Bidwell DE. Enzyme immunoassays for parasitic diseases. Trans $R$ Soc Trop Med Hyg 1976;70:98-106.

(Accepted 9 April 1981)

.

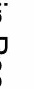

\section{.}

